\title{
MÚSICA I MÚSICS DEL BARROC CATALÀ. EL MESTRE DE CAPELLA DE LA SEU DE MANRESA, JOSEP MASVASÍ (1731-1762)
}

Glòria BALLÚs CASÓLIVA

\section{Resum}

El músic català Josep Masvasí fou mestre de capella de la Seu de Manresa (1731-1762). Malgrat aquesta llarga estada de 31 anys, tenim poques notícies de la seva producció musical, doncs només es conserva un Responsori per les Matines de Nadal (1733) i la informació de varis oratoris sacres que foren cantats a Manresa per la capella de música de la Seu. Una anàlisi d'aquest nocturn Verbum caro factum est ens mostra les tècniques compositives que utilitzava, oferint així un exemple d'aquest període del barroc musical català.

\begin{abstract}
The catalan musician Josep Masvasí was chapelmaster of Manresa cathedral (1731-1762). In spite of his staying there for a long while (31 years), we still have few records about his musical production. There ist only notice of one Responsory for Christmas' matins (1733) and scarce information on several sacred oratories composed by him, performed by the musical chapel of the cathedral in Manresa. The analysis of this nocturne, Verbum caro factum est, shows the compositional techniques he used, and provides us with an example of this concrete period of Catalonian baroque music.
\end{abstract}

\section{Dades biogràfiques}

Les noticies biogràfiques referents a aquest músic i compositor són minses i aïllades. Fins i tot el nom d'aquest músic es troba escrit a la documentació de l'època com a "Masvasî" i com a "Masvesî". No obstant això, he pogut trobar una carta autògrafa seva, conservada a l'Arxiu Històric Comarcal de Manresa, on el mateix compositor s'identifica com a "Masvasî", així com també a la portada de la única partitura seva que es conserva a l’Arxiu Musical de la Seu de Manresa (manuscrit 633). Per això em referiré a ell com a Josep Masvasí2.

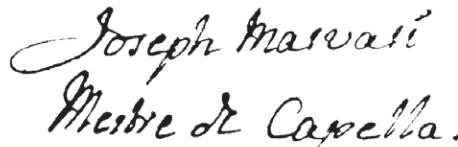

Signatura de la carta

1. Aquesta documentació forma part de la meva tesi doctoral La Música a la col-legiata basílica de Santa Maria de la Seu de Manresa: 1714-1808. Dades documentals per a la seva reconstrucció amb una aproximació al repertori litúrgic conservat, dirigida pel Dr. Antonio Ezquerro Esteban. Barcelona, UAB, 2004.

2. Normalitzo la forma antiga del nom "Joseph" i el transcric per "Josep". 
Malgrat les poques informacions referents a aquest músic conegudes fins ara, es coneixen algunes dades de la seva estada a Manresa, on va ocupar el càrrec de mestre de capella de l'església de Santa Maria de la Seu durant 31 anys (del 1731 al 1762).

L'historiador i arxiver manresà Joaquim Sarret i Arbós ${ }^{3}$, en el seu manuscrit titulat Fundació de la Capella de Música en la Iglesia Cathedral de Manresa ${ }^{4}$, dóna una sèrie de dades.

La primera noticia la tenim quan, faltant un mestre de capella a l'església de Manresa, el capítol de canonges va saber que a la ciutat de Barcelona hi havia un tal Josep Masvasí, que segons notícies podria ser apte per ocupar el càrrec; llavors el capitol de la Seu va encarregar al paborde Dr. Jacint Romanyà ${ }^{5}$ que es desplacés a Barcelona per conèixer Josep Masvasí, que s'informés sobre ell, i que donés una ràpida resposta al capítol sobre la seva aptitud per a la plaça.

Fins a l'any $1731^{6}$ el mestre de capella de la Seu manresana era Joan Mir (que ocupava el càrrec des del 1726), que deixà el càrrec. Mentretant, interinament, l'ocupà el reverent Sebastià Viladrosa, que actuava llavors com a organista.

Però el paborde Romanyà no va contestar al seu capítol com aquell esperava. Sobtadament, el dia 8 de desembre de l'any 1731, Josep Masvasí es presentà personalment davant el capítol de Manresa amb una carta escrita del paborde Romanyà amb informes favorables. No sabem el motiu d'aquest procedir, potser perquè Romanyà hagués tingut alguna indisposició o alguna gestió a fer a Barcelona, o que simplement, content amb Masvasí, li va encarregar directament presentar-se a Manresa, o si, per contra, Masvasí tenia certa pressa per ocupar la plaça.

Sigui com sigui, els canonges de la Seu resolgueren el dia 16 de desembre de 1731, per unanimitat de vots (i per tant, molt possiblement sense oposició), admetre el llicenciat Josep Masvasí per mestre de capella de l'església. Li donaren possessió del càrrec a partir del dia 18 de desembre i entrà a residir al cor el dia 18 de gener de l'any següent.

La carta escrita pel pabordre Romanyà que portava Masvasí al presentar-se al capítol, deia el següent:

“[...] Molt Iltre. Sr. = Aquesta serà per dir a V.S. com el donador d'aquesta és el llicenciat Josep Masvesi, deixeble del Sr. Mestre de l'església del Palau d'aquesta, i havent-me V.S. afavorit en donar-me la Comissió d'informar-me de dit llicenciat, i veure si era convenient per nostre església, he passat a conferir-me amb dit Sr. Mestre i de nou m'ha fet relació, expressant-me la seva habilitat de composició, la suficient veu que té pel cor, encara que no és de les més voltades i que espera es farà amb el temps; és també Organista; "algo" pràctic de tocar la viola i, últimament, m'ha dit que comprenia era convenient per l'església que d'altra manera hauria excusat, l'insinuar a V.S. tenia un deixeble, si no hagués comprés que era de tot desempenyo. I sabent, per altre part, que dit llicenciat actualment feia de Mestre de Cor a l'església de Santa Anna d'aquesta, no he deixat d'informar-me del seu procedir, del qual m'han donat molt bones noticies i que, en dita església, n'estaven contentíssims. Atenent a dits informes he continuat

3. Joaquim Sarret i Arbós (*Manresa, 04.08.1853; †Id., 26.09.1935).

4. SARret i Arbós, Joaquim: Fundació de la Capella de Música en la Iglesia Cathedral de Manresa. Manuscrit, 1919, Arxiu Històric Comarcal de Manresa, Fons Sarret i Arbós, apartat d'escrits inèdits, amb signatura vi/120. Aquest document està transcrit íntegrament $\mathrm{i}$ ha estat objecte d'estudi en la meva tesi doctoral.

5. Jacint Romanyà i Castells fou Paborde de la col-legiata manresana de 1724 a 1781 .

6. En el Llibre de Quotidianes Distribucions figura com al seu últim pagament, el salari corresponent a la $3^{\text {a }}$ terça de l'any 1731 . 
la Comissió V.S. fou servit donar-me de presentar nostre Magisteri, a dit llicenciat Josep Masvesi, en nom de V.S. el que espero tindrà a bé aquesta elecció. Quedant en l'interin suplicant ocasions del seu major agrado i al Cel el g. ${ }^{\text {de }} \mathrm{m}^{\mathrm{o}}$ an $^{\circ}$ Barcelona, a 8 de desembre de $1731=$ B. la M de V.S. el seu segur servidor D. Jacinto Romanyà, paborde de Manresa =".

Per aquest escrit coneixem que Masvasí: fou deixeble del mestre de l'església del Palau de la Comtessa de Barcelona (?) ${ }^{7}$, el qual va informar favorablement sobre ell al paborde Romanyà; componia, cantava amb suficient competència, era organista i tocava la viola. En el moment del seu trasllat a Manresa feia de mestre de cor a l'església de Santa Anna de Barcelona.

Poc temps després de començar a regir el magisteri a Manresa fou ordenat sacerdot, segons indica Sarret i Arbós en el seu manuscrit ${ }^{8}$.

A la col-legiata manresana, Josep Masvasí va obtenir el benefici (que fou fundat l'11 d'agost de 1724 i en poder del notari Josep Comas, de Vic) sota la invocació del Sant Esperit per Ignasi Mollet de la Plana, substituint al primer obtentor que fou Ignasi Mollet (que morí l'1 de desembre de 1739).

Però al voltant de les seves obligacions com a mestre de capella (compondre, ensenyar els minyons, dirigir el cor, acompanyar les visites i fer les ambaixades del capítol, etc.), el Rnt. Masvasí també va ésser l'encarregat de vendre el secret vell de l'orgue de l'església, com se li va ordenar per resolució de la comunitat de canonges de la Seu, el dia 6 de maig de $1763^{9}$. El va vendre per vint-i-cinc lliures barcelonines.

El 27 d'abril de l'any 1762 cessà com a mestre de capella i el va substituir el Rnt. Salvador Dachs ${ }^{10}$. Desconeixem encara el motiu d'aquesta substitució, tot i que podem imaginar algunes hipòtesis: un possible mal estat de salut, una presumible edat avançada, o si més no, la jubilació del càrrec.

La substitució del càrrec queda reflectida en la pòlissa ${ }^{11}$ firmada el 12 de juny d'aquell any 1762:

"Dit dia s'ha fet pòlissa al Rnt. Josep Masvesi i al discret Salvador Dachs, mestres de capella de la quantitat de $£ 123 \varphi 4$, això és $£ 51 \varphi$ pels 26 dies que en el mes d'abril pròxim passat ha exercit la feina de Mestre de Capella, a raó de $£ 1710 \varphi$ per la terça del seu salari, i $£ 72 \varphi$ 3, al discret Salvador Dachs per haver exercit dita feina des del 27 d'abril fins el 30 de juny de 1762, tots inclusiu i a raó de $£ 10$ per terça".

El Rnt. Josep Masvasí va morir el 29 de setembre de l'any 1774 (dotze anys després de deixar el magisteri), al carrer del Born de Manresa, i com a beneficiat de l'església fou sepultat a la mateixa $\mathrm{Seu}^{12}$. A la seva hereva, Caterina Dalmau (?), se li pagà el subsidi de la infermeria [espècie de germandat de beneficiats] per trenta-un dies, des del 19 d'agost al 13 de setembre, com a convalescent, i per cinc dies, des del 24 al 28 de setembre, des que fou novament combregat i fins que morí.

7. Codina, Daniel: "La música vocal d'església en el classicisme”, a Historia de la Música Catalana, Valenciana i Balear. Vol. II "Barroc i Classicisme". Barcelona. Edicions 62, 1999, p. 148.

8. SARret i Arbós, Joaquim: Fundació de la Capella de Música..., op. cit., sense foliar

9. Llibre de Resolucions / de la Rnt. Comunitat / de la Seu de Manresa, p. 213 [06.05.1763].

10. En el Llibre de Quotidianes Distribucions s'indica la quantitat que va cobrar pels 26 dies del mes d'abril de 1762.

11. SARret i ARbós, Joaquim: Fundació de la Capella de Música..., op. cit., sense foliar

12. Llibre d'Òbits de 1767 a 1781, a l'Arxiu Parroquial de Manresa. [Anotació de Joaquim Sarret i Arbós en el seu manuscrit]. 
Joaquim Sarret i Arbós, en el seu manuscrit Fundació de la Capella de Música en la Iglesia Cathedral de Manresa ${ }^{13}$, transcriu la seva partida de defunción ${ }^{14}$ :

“[...] dijous a 29 de setembre de l'any 1774, en el carrer del Born, en la casa de la seva habitació, entre vuit i nou hores del matí, morí el Rnt. Josep Masvesí prevere i beneficiat de la present església, després d'haver rebut els Sants Sagraments. Ha fet testament en poder del Dr Josep Enrich, notari de Manresa, i li feren sepultura de beneficiat i el dia següent fou sepultat a la Seu”.

Pel que coneixem fins a aquest moment, l'àmbit d'actuació respecte a aquest compositor és molt reduït. Quasi no existeix bibliografia específica ${ }^{15}$ i tan sols coneixem una composició musical seva, conservada a l'Arxiu de la Seu de Manresa.

Pel que podem dir fins ara, la seva formació i els llocs on va exercir la seva activitat foren únicament Barcelona, a la petita església parroquial de Santa Anna -poc rellevant en aquella època des del punt de vista musical- i Manresa; per tant un àmbit d'actuació molt reduït. No obstant això, sabem que gaudia d'una molt àmplia versatilitat musical, característica d'altra banda molt freqüent a l'època que li va tocar viure: sabia de composició, tenia bona veu per cantar, era organista i, a més, també tocava la viola.

Tan sols a manera d'hipòtesi, se li pot aventurar un possible origen barceloní: va ésser deixeble del mestre del Palau de la Comtessa (com a minyó o corer d'aquella església?), va exercir com mestre a Santa Anna de Barcelona, i quan arriba a Manresa, procedeix també de Barcelona. Tampoc sabem quan temps va estar a Santa Anna com a mestre de cor, ni si va entrar allà per oposició o no. En tot cas, el seu mestre sembla tenir un bon concepte professional d'ell, com es demostra per les seves informacions al capítol manresà.

\section{Consideracions sobre el seu magisteri}

Josep Masvasí va ser durant 31 anys mestre de la capella de música de la Seu manresana.

Al cap de set anys de prendre possessió del càrrec, es va plantejar reformar la seva capella de música, a fi que les funcions tinguéssin més solemnitat. Per això, va demanar que fossin admesos a la capella els músics més experts de la ciutat. El Capítol admeté com a bona la seva proposta i, com indica la resolució del 20 d'abril de 1738, foren acceptats de seguida els músics Josep Auger (teixidor de llana), Josep Rosinyol (peraire), Joan Codina (teixidor de llana), Miquel Pascual (peraire) i Rafel Pagés (teixidor de 1li) ${ }^{16}$, amb l'obligació d'assistir a totes les festivitats de l'església amb els seus respectius

13. SARret i Arbós, Joaquim: Fundació de la Capella de Música..., op. cit.

14. Del Llibre d'Òbits de 1767 a 1781, a l'Arxiu Parroquial de la Seu.

15. VILAR, Josep Maria: La música a la seu de Manresa en el segle XVIII. Manresa, Centre d'Estudis del Bages, 1990. ID.: "Masvesí", a Diccionario de la Música Española e Hispanoamericana. Madrid, SGAE, 2000. Volum 7, p. 344.

16. Observem que els cinc músics, considerats els "més experts de la ciutat" eren precisament, tres teixidors i dos peraires. Això vol dir que cap d'ells tenia la música com a activitat principal, ja que es dedicaven habitualment a la important indústria tèxtil manresana, símptoma del lloc que corresponia a la música a la societat hispànica de l'època. Per una banda, el capítol es mostra interessat a contractar fins i tot cinc músics (!), els més experts de la ciutat, però, per altra banda, aquests músics es dedicaven a una altra activitat professionalment. 
instruments ${ }^{17}$. Així, Masvasí va aconseguir dotar la Seu d'un grup instrumental estable, integrat al menys per cinc instrumentistes.

Aquest interès per "actualitzar" la capella sota les seves ordres diu molt de les seves pretensions professionals i del seu compromís amb la capella i amb l'església a la qual pertanyia, però, sobretot, amb la música que es feia al seu temps.

A partir, doncs, del 1738 queda establert a la Seu de Manresa un grup instrumental permanent, per a garantia i lluïment de les celebracions no tan sols litúrgiques, sino també paralitúrgiques, cosa que aporta unes noves possibilitats expressives als compositors i, en definitiva, al capítol manresà. A partir de llavors, els ministrils i els cantors de la capella podrien interpretar un ventall molt més ampli de partitures de la literatura internacional, com també desenvolupar els propis recursos expressius. S'obria un camp de possibilitats musicals que fins llavors no hi era.

\section{Les obres}

De la seva producció musical només es conserva una única partitura a l'Arxiu de Manuscrits Musicals de la Seu de Manresa, datada al 1733, quan feia dos anys que n'era mestre de capella.

Responsori 2n del 3r Nocturn de Matines de Nadal, Verbum caro (1733), a 6 veus i acompanyament ( $E: M A N$, Ms.633):

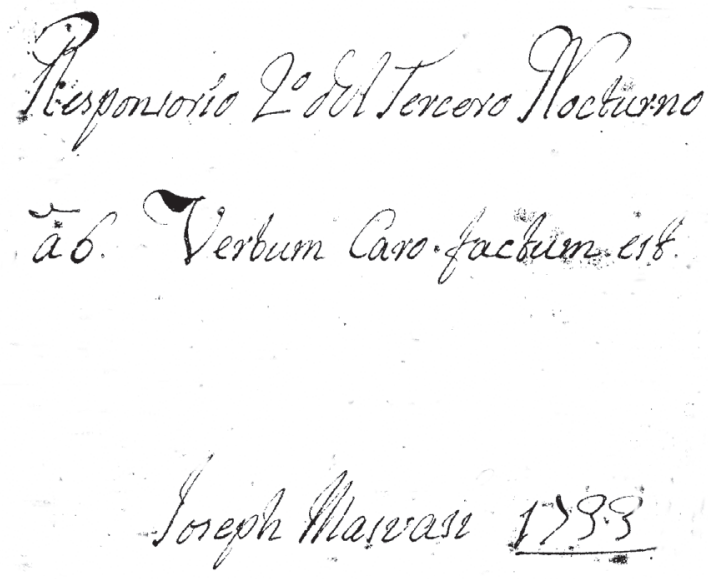

\section{Portada del manuscrit}

17. No s'indica en la resolució quins eren els instruments que tocaven. A la documentació conservada no s'especifica mai quins instruments tocaven. Per tant, voldria dir que no semblava rellevant concretar el tipus d'instrument, com també, potser, que tocaven més d'un instrument. 
A part de la seva producció musical conservada (una única partitura), és important també indicar que, gràcies a dos impresos dels llibrets conservats a la Biblioteca Nacional de Madrid, sabem que Masvasí va compondre almenys dos oratoris ${ }^{18}$ a Manresa i per a dues festivitats importants.

El primer d'aquests oratoris, El Monarca protector -anomenat "oratorio sacro"- fou cantat per la Capella de música de la Seo manresana els dies 8 a l'11 de maig de 1745, dedicat al rei Felip V i destinat al col·legi ${ }^{19}$ manresà de Sant Ignasi, dels jesuïtes.

"El Monarca protector: oratorio sacro que con alusion a las honras y finezas del Rey Salomon con Sunamitis, aplaude la real protección, con que el Rey N. S. D. Phelipe V el Animoso (Dios le guarde) ha honrado de nuevo a su Congregación del Corazón de Jesus, y Concepcion de Maria fundada en el Colegio de S. Ignacio de la Compañía de Jesus de la ciudad de Manresa en los [...] cultos que [...] consagra a sus SS. Titulares en la misma Iglesia [...] en los dias 8, 9, 10, 11 de Mayo de 1745 / cantòlo la Capilla de la Seo de Manresa; siendo su Maestro [...] Joseph Masvesi [...] - Barcelona: en la Imprenta de Juan Piferrer, [1745?]"20. [Aquesta obra es compón de les següents parts : 1. Escena I: Al Rey de dos Orbes los dos elogiad; 2. Escena II: Qué rabia sangrienta, celoso despecho; 3. Escena III: Ya que las sombras nocturnas]. E: Mn.

El segon oratori, La nave del mercader"21 -anomenat "drama alegórico"- estava destinat al Convent $^{22}$ de Santa Clara de Manresa -dominiques de clausura-, i fou interpretat per la Capella de música de la Seu el dia 29 de maig de 1747, en la professió d'una monja.

"La Nave del mercader: drama alegorico, que en la professión, y velo de la señora Sr. Maria Josepha Vandanent, y Andreu, en el [...] Convento de Nuestra Señora de los Angeles, y Santa Clara, de Religiosas

18. Veure: CARreras Bulbena, Rafael: El oratorio musical. Barcelona, L’Avenç, 1906, p. 140; Codina Giol, Daniel: "La música vocal d'església en el barroc", a Història de la Música Catalana, Valenciana i Balear. Vol. II "Barroc i Classicisme". Barcelona, Edicions 62, 1999, p. 40; ID.: "La música vocal d'església en el classicisme", a Història de la Música Catalana, Valenciana i Balear. Vol. II "Barroc i Classicisme". Barcelona, Edicions 62, 1999, p. 148; DAufí, Xavier: Estudi dels oratoris de Francesc Queralt (1740-1825). Fonaments de la història de l'oratori a Catalunya al segle XVIII. Tesi doctoral. Barcelona, Universitat Autònoma de Barcelona, 2001; ID.: "Historia del oratorio en Catalunya en el siglo XVIII", a Revista de Musicologia, XXVI/1 (2003), pp. 207-231; RIFÉ SANTALÓ, Jordi: "La música religiosa en romanç en el barroc", a Història de la Música Catalana, Valenciana i Balear. Vol. II "Barroc i Classicisme". Barcelona, Edicions 62, 1999, p. 93.

19. Per conservar el record de l'estada d'Ignasi de Loiola a Manresa i per tal de tenir una presència continuada dels Pares de la Companyia de Jesús, els Consellers de la ciutat varen cedir, el 15 d'abril de 1602, l'edifici de l'antic hospital de Santa Llúcia als jesuites per fundar la seva residència i un col-legi d'ensenyament. Per ampliar informació veure: SARRET I ARBós, Joaquim: Historia religiosa de Manresa. iglésies $i$ convents, Manresa, Impremta i enquadernacions de Sant Josep, 1924, pp. 218-234; i Bajona Oliveras, Ignasi: L'antic Col-legi de Sant Ignasi de Manresa. Una crònica de les seves vicissituds. Manresa, Centre d'Estudis del Bages, 1997.

20. Veure: Guillén Bermejo, María Cristina; i Ruiz de Elvira Serra, Isabel; coords.: Catálogo de Villancicos y oratorios en la Biblioteca Nacional. Siglos XVIII-XIX. Madrid, Biblioteca Nacional, 1990, p. 425 (número 1166, p. 425, signatura VE/1305133). El catàleg diu que aquest oratori va ser interpretat del 8 a l'11 de maig, mentre que un recent treball (CoDINA I GiOL, Daniel: "La música vocal d'església en el classicisme", a Història de la Música Catalana, Valenciana $i$ Balear. Vol. II "Barroc i Classicisme". Barcelona, Edicions 62, 1999, p. 93) ens diu que va ser interpretat del 8 a 1'11 de juliol a la Cova de Sant Ignasi de Manresa. No s'han pogut confirmar les dates exactes de l'execució de l'oratori i quina festivitat celebrava la referida "Congregación del Corazón de Jesús y Concepción de María" (fundada en l'esmentat col-legi). Cal tenir en compte que el titular de la església de la Companyia de Jesús a Manresa és solament Sant Ignasi de Loyola i, per altra banda, els patrons titulars de la ciutat, Santa Agnès, Sant Maurici i Sant Fruitós, no celebren les seves festivitats ni al maig ni al juliol (?).

21. Veure: Guillén Bermejo, María Cristina; i Ruiz de Elvira Serra, Isabel; coords.: Catálogo de Villancicos y oratorios en la Biblioteca Nacional. Siglos XVIII-XIX. Madrid, Biblioteca Nacional, 1990, p. 425 (número 1167, p. 425, signatura $\mathrm{VE} / 1304-94)$. 
Dominicas de [...] Manresa / cantò la Capilla de la Seo de dicha ciudad; siendo su maestro el Licenciado Joseph Masvesi. Dia 29 de mayo 1747. - Barcelona: por Francisco Surià [...], [1747?]. [Aquesta obra es compón de les següents parts : 1. Escena Primera: De las playas del mundo engañoso; 2. Escena Segunda: ¡Ay, cómo corre!, ;ay, cómo vuela!; 3. Escena Tercera: Ya la nave augusta]. E: Mn.

Els dos llibrets es van publicar a Barcelona; el primer es va imprimir a les oficines de Joan Piferrer i el segon a l'establiment de Francesc Surià.

Segurament devien ser composicions que Masvasí va fer per encàrrec per a les dues festivitats, que ens parlen de les que devien ser les seves habituals activitats durant els trenta-un anys del seu mestratge a Manresa.

Cal remarcar que tots dos estan escrits en castellà, malgrat que s'interpretessin a Manresa i fossin destinats a dues institucions religioses manresanes.

També hi ha un llibret de Josep Masvasí a la Biblioteca de Catalunya, en el Fons "Bonsoms y Aguiló" (1670-1800), dins la col-lecció "Folletos Aguiló"23. Es tracta d'un altre imprés -indicat com a "drama sacro"- títulat El Monarca protector" i amb l'íncipit literari "Al Rey de dos orbes los dos elogiad", que seria el mateix llibret que figura a la Biblioteca Nacional de Madrid, encara que imprés en una altra impremta (a la impremta Herederos de Juan Pablo Martí).

"El Monarca protector. / Drama Sacro. / Que con alusión a las honras, y finezas ... con que el Rey N. S. D. Phelipe V, el Animoso, ha onrado ... a la Congregación del Corazon de Jesus, y Concepción de Maria ... en el Colegio de S. Ignacio ... de Manresa ... accion de gracias en los dias 8.9.10.11. de Mayo 1745. / Cantòlo la Capilla de la Seo de Manresa siendo su Maestro / el Licenciado Joseph Masvesi. / ... ScenA 1. Coro 1. "Al Rey de dos Orbes los dos elogiad" / f.157-160. ... Barcel. En la Imprenta de los Herederos de Juan Pablo Martì. FA-2, 28 - 1166.” E: Bbc

\section{Consideracions sobre la seva obra compositiva}

En referència a les seves composicions, desconeixem on pot ser el gruix de la seva obra ${ }^{24}$, ja que malgrat tenir el càrrec de mestre de capella de la Seu manresana durant trenta-un anys, només s'hi conserva una partitura (ja indicada): el Responsori segon del tercer Nocturn de Matines, Verbum caro, de l'any 1733.

22. El convent de Santa Clara té el seu origen a l'any 1322, quan el Pabordre de Santa Maria va donar permís de construir una casa prop l'indret de la Culla per les monges de Santa Clara, seguint el testament de Berengària, viuda d'Arnau d'Olm, jurispèrit de Manresa; i des del 1602 amb monges dominiques dels Àngels de Barcelona. Per ampliar informació, veure: SARRET i ARBós, Joaquim: Historia religiosa de Manresa. iglésies i convents. Manresa, Impremta i enquadernacions de Sant Josep, 1924 , pp. $239-251$.

23. Pavia, Josep: La Música en Catalunya en el siglo XVIII. Francesc Valls (1671c-1747). Barcelona, CSIC, 1997, pp. 39-169. [Cita concreta a pp. 88, 119, 133, 150, 156, 157, 159 i 164]. L'obra es classifica dins el treball de Pavia en el apartat anomenat "Dramas" i amb la signatura FA-1, 28.

24. He pogut revisar els catàlegs de diferents indrets d'arreu de Catalunya, sense trobar cap altra informació o notícia de les seves composicions.

25. Segons les normes del RISM l'obra consta de: $6 \mathrm{~V}$ (Coro 1: S, T; Coro 2: S, A, T, B); acompanyament. A més, tots els 
El manuscrit musical ${ }^{25}$ es conserva en set papers solts que corresponen a les particel-les destinades a les següents parts: Tiple $1 \mathrm{r}$ cor, Tenor $1 \mathrm{r}$ cor, Tiple $2 \mathrm{n}$ cor, Contralt $2 \mathrm{n}$ cor, Tenor $2 \mathrm{n}$ cor, Baix ${ }^{26}$ 2n cor i acompanyament continu.

És interessant indicar que darrere la particel-la que correspon al Tiple del 1r cor hi ha escrit Anzon $^{27}$, Joseph Fabres ${ }^{28}$; i la particel-la de Tenor diu Caratxoli ${ }^{29}$, segurament el nom dels corers (nens cantors) que l'havien cantat, cosa que demostra que era una partitura que s'havia interpretat en diferents ocasions i anys.

Aquest manuscrit té la marca de paper o filigrana següent ${ }^{30}$ :

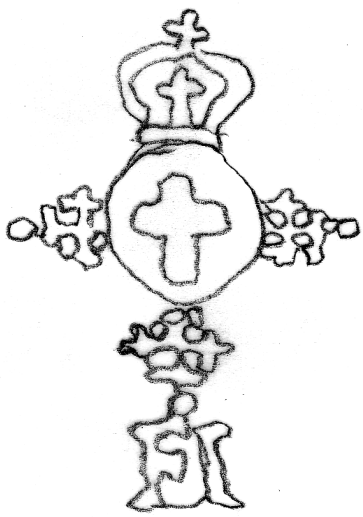

\section{Filigrana}

Per aquesta obra podem veure com Masvasí viu encara en un món a cavall entre els segles XVII i XVIII. Així per exemple, fa servir el signe de proporció menor, els ennegriments de la notació, les corxeres de cap blanc pròpies d'aquest compàs, etc. Tampoc aplica les línies divisòries d'una forma sistemàtica (en ocasions es veuen afegides a posteriori fins i tot, creant notes "partides", o apareixent cada dos o tres tactus, més o menys aleatòriament...).

papers tenen indicat a llapis "Seu Manresa Ms 114" que correspon a la signatura provisional indicada en la catalogació de Josep Ma. Vilar.

26. En el manuscrit no figura el text que correspon al Baix del segon cor, fet que sembla indicar que era interpretat per un o més instruments. Segons Josep Pavia (en PAVIA, Josep: La Música en Catalunya en el siglo XVIII. Francesc Valls (1671c-1747). Barcelona, CSIC, 1997, p. 33-38) la veu del "Baix" se suplia amb l'instrument "bajón", i concreta: "sobre todo cuando se trataba de música policoral y de hecho muchas obras así lo indican, bien haciendo constar que lo hace un instrumento, bien no escribiendo el texto en la partichela". [Cita concreta, p. 35].

27. No figura en els Llibres de Quotidianes Distribucions d'aquesta època.

28. Segons el Llibre de Quotidianes Distribucions, del 1742 al 1749 hi va haver un corer que es deia Josep Fabres. Caracholi.

29. Segons els llibres de Quitidianes Distribucions, del 1773 al 1779 hi va haver un corer que es deia Jaume Caratxoli o

30. Aquest marca de paper o filigrana no queda reflectida en cap dels llibres que he pogut consultar i per tant no puc establir la seva procedència, ni familiar ni de lloc.

31. La paraula "part" que s'indica per analitzar l'obra pot dir-se també "moviment" o "secció", sempre entès com a dife- 


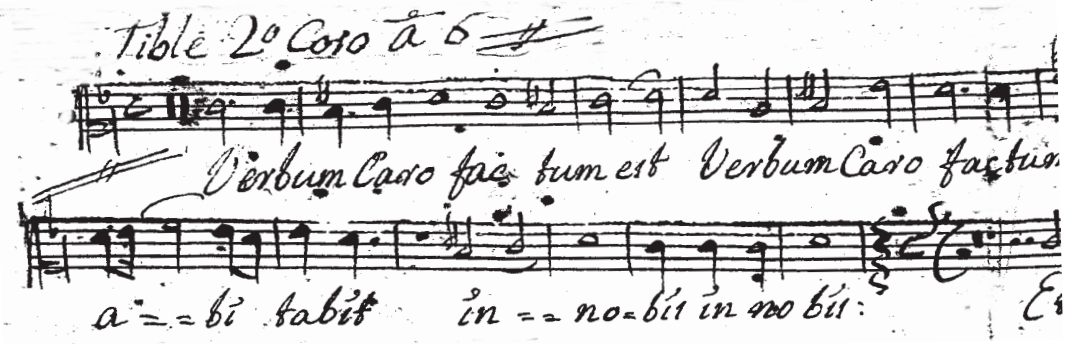

Tiple del 2n cor

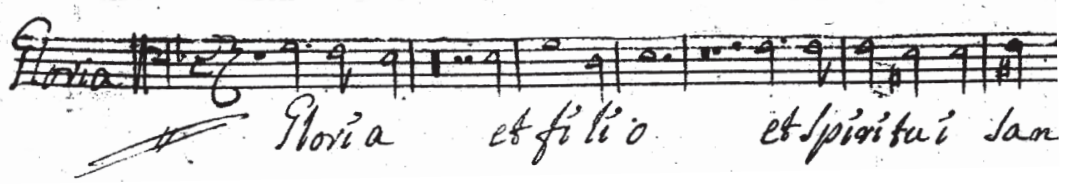

Tenor del $2 n$ cor

L'obra, que toda ella és el Responsori pròpiament dit, està dividida en tres parts ${ }^{31:}$ Responsori, Verset i Doxologia menor. La primera part té 36 compassos en compàs binari i 32 compassos en compàs ternari; i que juntament amb el verset i la doxologia (que no canvia) fa una alternança de compàs binari-ternari-binari-ternari. Podriem suposar la relació del binari-ternari com la dels números 2-3 (relació entre el número natural o humà i el número sobrenatural o diví), que coincideix amb el text referit a "l'home" (binari) o a "Déu i la seva glòria" (ternari).

\begin{tabular}{|c|c|c|c|}
\hline \multicolumn{2}{|c|}{ Responsori } & Verset & Doxologia menor (Glòria) \\
\hline compàs binari & compàs ternari & compàs binari & compàs ternari \\
\hline $36 \mathrm{c.}$ & $32 \mathrm{c}$. & $13 \mathrm{c}$. & $22 \mathrm{c}$. \\
\hline \multicolumn{3}{|c}{} & $103 \mathrm{c}$. \\
\hline
\end{tabular}

El compositor utilitza dues formes com a procediment; l'entrada escalonada de les veus (en el Responsori) i la simultaneitat de les veus (dues en el verset i totes sis en la Doxologia menor). 


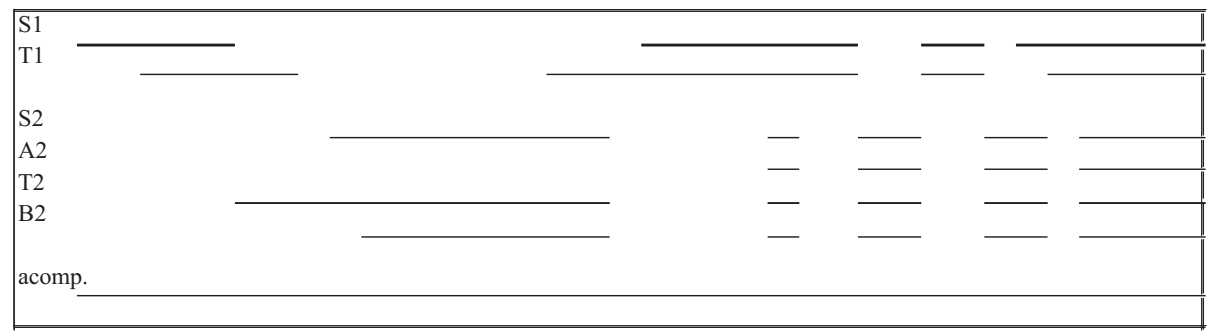

Estructura vocal i instrumental (intervencions)

En aquesta obra intervenen dos cors que en una primera part fan l'entrada de les veus de forma escalonada S 1, T 1, T 2, S 2, B 2, A 2, T 1, S 1. En la segona part les veus del segon cor canten simultàniament però en forma dialogant amb les veus del primer cor. Només l'acompanyament intervé de forma continuada durant tota l'obra.

Cal remarcar l'alternança entre els dos cors: primer les dues veus del primer cor i les quatre veus del segon cor, repetint una altra vegada aquesta alternança. Aquests canvis de sonoritat i la repetició de versets dóna força al text, que encara queda més reafirmat quan hi han les sis veus simultàniament.

Al final de les entrades de les veus hi ha un bloc de totes les 6 veus (nobis) (nosaltres). El text més repetit és Verbum caro factum est (la Paraula es va fer home) que es repeteix deu vegades; et Spiritui Sancto (i l'Esperit Sant) que també es repeteix deu vegades; i et veritatis catorze vegades, com per reafirmar el text important d'aquest responsori, si tenim en compte que correspon a Nadal. Reafirma que "la Paraula es va fer home, per obra de l'Esperit Sant i que és veritat". Aquest podria ser el missatge que el compositor va voler remarcar.

És una obra més funcional (destinada a complir un determinat paper en la celebració litúrgica de Nadal amb eficàcia) que de grans pretensions artístiques. Es tracta d'una obra només a veus i acompanyament, sense orquestració. Els àmbits són reduïts i l'extensió més aviat és discreta, ja que té 103 compassos.

No obstant això, cal pensar que és una obra condicionada pel marc litúrgic, ja que és tracta del Responsori 8è, el penúltim d'una sèrie de nou, cosa que fa que tampoc pugui ser massa llarga. Es canta a les matines del dia de Nadal després de 8 antífones, 8 salms, 8 lliçons i 7 responsoris; per tant no sembla massa adient que tingués una amplitud més gran.

En relació al text cal remarcar que és el que més importa, per sobre de la música. Precisament és el compositor qui està condicionat a seguir el que significa el text, encara que es pot sentir còmode en la seva composició atès que al ser un Responsori està relativament menys encorsetat i no està subjecte a la severitat litúrgica d'altres peces. Fa un tractament musical personal, i fins i tot relativament lliure, el que s'adequa molt més al context de les matines per al dia de Nadal, pensem que no és una missa que té una litúrgia més severa, i precisament el dia de Nadal és un dia més alegre, festiu...

El text, pel que hem pogut constatar, no ha estat massa musicalitzat per compositors de l'època. Per tant, existeixen pocs elements de comparació possibles. El que voldria dir que la seva pròpia musi- 
calització queda per tant dins una certa "originalitat" per part del compositor, però al mateix temps denota certa "marginalitat".

Quant al tractament de la composició, aquesta s'anota per a sis veus en dos cors, d'una forma, per atípica, típicament "barroca": solament dues veus al primer cor (Tiple i Tenor), que canten el verset a manera de solistes, i quatre veus al segon cor (Tiple, Contralt, Tenor i Baix).

En contrapartida a l'interès que veiem en Masvasí per donar una major importància als instruments, precisament, aquesta composició peca de manca de presència instrumental (?!), si no fos pel baix continu, anomenat tan sols com "Acomp[añamien]to Cont[inu]o". En descàrrec de Masvasí es pot dir que aquesta obra -que per altra banda s'ha de tenir en compte que és un Responsori-, pertany a l'any 1733, cinc anys abans de la seva proposta al capítol en el sentit que convenia contractar nous instrumentistes, potser perquè al llarg dels seus primers anys com mestre a Manresa, Masvasí va adonar-se de la necessitat d'evolucionar cap a una música més "moderna".

Per últim, i com característica moderna de l'obra, podem fixar-nos en el xifrat aplicat al paper corresponent al baix continu, que apareix molt desenvolupat, és a dir, amb moltes "xifres" (en contraposició a la manca de números als continus habituals durant el segle XVII a l'àmbit hispànic, que tan sols afegiran més i més "xifres" amb el pas del temps).

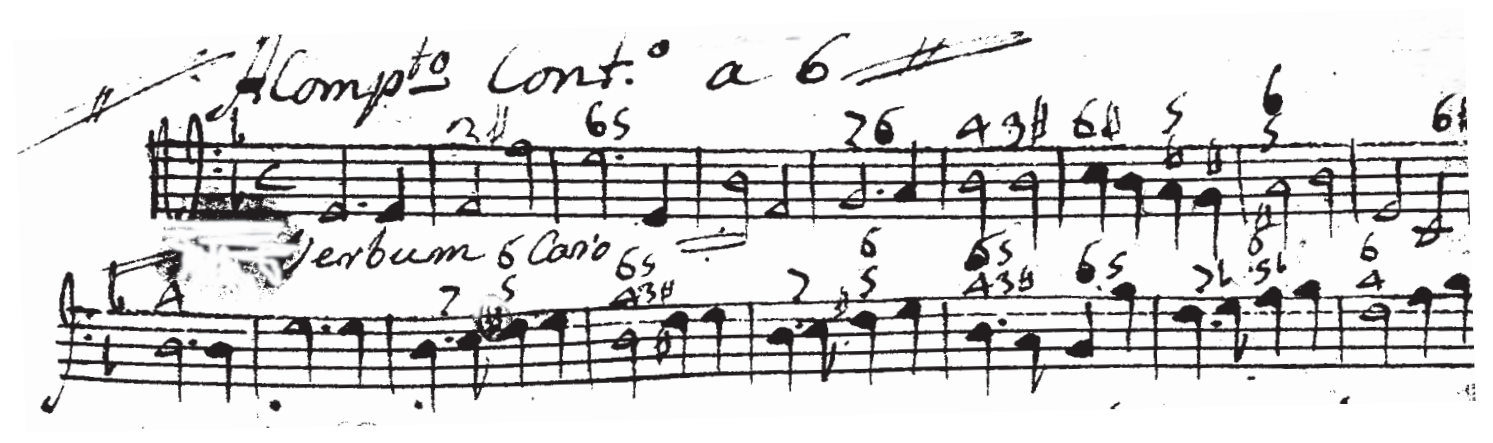

Baix xifrat

No cal perdre de vista que Masvasí va ocupar el magisteri principal de la ciutat de Manresa durant quasi un terç de segle, un període suficientment extens com per condicionar les "maneres" de fer en matèria musical a posteriori. Però, malgrat això, és francament difícil extreure conclusions vàlides únicament a partir d'una composició, encara que és interessant per tot el que he indicat. Molts anys, però pocs materials.

No obstant això, no hi ha dubte de que la manera de treballar, tant el text com la música, ens apropen a un compositor que coneix molt bé les tècniques de la composició, sobretot de cara a fondre-les, d'una manera eficaç, amb el context litúrgic pel qual la composició havia estat concebuda. 